
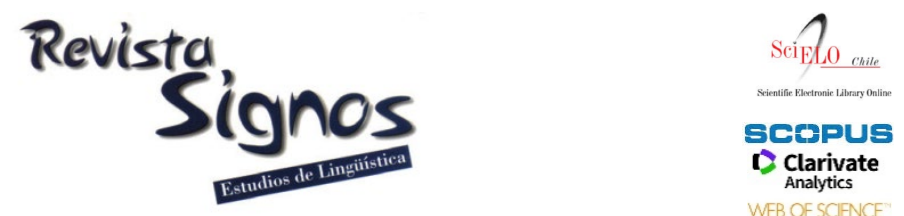

WEB OF SCIENCE

\title{
Tiempos verbales y puntos de vista evidenciales citativos: Acerca de los valores citativos del futuro, del condicional y del imperfecto ${ }^{1}$
}

\author{
Tenses and evidential points of view: Quotative uses of the \\ future, the conditional and the imperfect
}

\author{
María Marta García Negroni \\ UNIVERSIDAD DE SAN ANDRÉS / CONICET \\ ARGENTINA \\ mgarcianegroni@udesa.edu.ar / mamagn@gmail.com
}

Recibido: 12-08-2020 / Aceptado: 24-02-2021

DOI: $10.4067 /$ S0718-09342021000200376

\section{Resumen}

En este trabajo, y a la luz del Enfoque dialógico de la argumentación y de la polifonía, se analizan los empleos citativos del futuro (morfológico y perifrástico), del condicional (periodístico y científico) y del imperfecto. Según se argumenta, estos empleos vehiculizan 'puntos de vista evidenciales' que, en tanto tales, comportan instrucciones dialógico-causales que obligan a identificar la causa evidencial de la enunciación en la que se expresan en 'marcos de discurso' previos. Constituidos por encadenamientos argumentativos en los que una determinada representación discursiva de un decir evocado queda articulada normativa o transgresivamente con distintas aserciones respecto de ese decir, dichos marcos de discurso permiten explicar los distintos posicionamientos subjetivos plasmados en la enunciación. La aproximación al significado citativo del futuro morfológico, del futuro perifrástico, del condicional periodístico, del condicional científico y del imperfecto, que aquí se propone, permite explicar las propiedades que, en cada caso, reviste la enunciación (enunciación concesiva, refutativa, precavida y resguardada, distanciada, confiada pero prudente). Asimismo, permite dar cuenta de la imagen del decir que queda evocado en cada caso (como un decir plausible pero solo en parte acertado y justificado, como algo inadmisible, como un rumor que todavía no puede darse por cierto, como un decir calificado o como un decir confiable).

Palabras Clave: Punto de vista evidencial citativo, marco de discurso, posicionamiento subjetivo, citativo, tiempos verbales. 


\begin{abstract}
Framed within the Dialogic Approach to Argumentation and Polyphony, this paper offers an analysis of the quotative uses of the future (morphological and periphrastic), the conditional (journalistic and scientific) and the imperfect. It will be contended that the uses studied convey 'evidential points of view', which, as such, carry dialogic-causal instructions that make the interpreter identify the evidential cause of the enunciation in a previous 'discourse frame'. Discourse frames are constituted by argumentative sequences in which certain discursive representations of an evoked discourse are articulated normatively or transgressively with different assertions concerning that discourse. An analysis of discourse frames may account for the subjective positions evident in the enunciation. The proposed dialogic and argumentative approach to the quotative meaning of the morphological future, the periphrastic future, the journalistic conditional, the scientific conditional and the imperfect is instrumental to explain the diverse linguistic properties of the enunciation (concessive, refutative, careful and guarded, detached, trusting but cautious). By the same token, this approach can be applied to determine the image of the discourse that is evoked in each case (as a plausible saying but only partially correct and justified, as something inadmissible, as a rumor that cannot yet be taken for granted, as a qualified saying or as a reliable saying).
\end{abstract}

Key Words: Evidential point of view, Discourse frame, Subjective position, quotative, tenses.

\title{
INTRODUCCIÓN
}

Como es sabido, la evidencialidad suele definirse como el dominio semántico relacionado con la marcación e identificación de la fuente de la información que el hablante comunica en su enunciado (Aikhenvald, 2004). Según la concepción tradicional de Willett (1988), se considera que dicha fuente es directa si el conocimiento de lo que el hablante dice proviene de una percepción originada en alguno de sus sentidos (evidencia directa sensorial), e indirecta si ese conocimiento procede de una inferencia (evidencia indirecta inferida) o de una cita de un discurso ajeno (evidencia indirecta transmitida o referida). En el caso de la inferida, sostiene Willett (1988), la información en la que el hablante basa su inferencia es o bien una evidencia observable, o bien un razonamiento o construcción mental. En el caso de la evidencia indirecta transmitida, la información comunicada puede proceder de los dichos de una persona específica (segunda o tercera mano) o del folclore o saber popular. ${ }^{2}$

Según sea directa o indirecta, sostienen algunos investigadores con una concepción 'amplia' de la evidencialidad (en inglés, evidentiality in a broad sense), la fuente implica distintos grados de confiabilidad, los que a su vez determinan distintas actitudes epistémicas del sujeto hablante frente a lo que dice (Chafe, 1986; NGLE, 2009). Esta relación de inclusión en la que uno de los términos se entiende en el alcance del otro no es, sin embargo, la única posición respecto de las relaciones que pueden establecerse entre evidencialidad y modalidad. En efecto, tal como se señala en la bibliografía sobre el tema (Dendale \& Tasmowksi, 2001), para otros autores, la 
relación es de disyunción o de solapamiento. En el primer caso, la evidencialidad y la modalidad epistémica son concebidas como categorías independientes (De Haan, 1999; Aikhenvald, 2004; Cornillie, 2007, entre otros), dado que -según se señala- no siempre puede establecerse una correlación biunívoca constante entre tipo de evidencialidad y grado de compromiso epistémico. En el segundo caso, y aunque se admite que evidencialidad y modalidad constituyen categorías independientes, se insiste en la existencia de un solapamiento entre ambas cuando de lo que se trata es de la evidencialidad inferencial (Van der Auwera \& Plungian, 1998).

Las lenguas varían en cuanto a la manifestación de la evidencialidad. Como es sabido, algunas, como el tuyuca o el quechua, cuentan con distintos morfemas que especifican si el hablante fue testigo directo de los hechos que narra, si los infirió o si oyó acerca de ellos por boca de terceros. Otras, como el español, no gramaticalizan de manera obligatoria los significados evidenciales, pero disponen, en cambio, de recursos que permiten el despliegue, en ciertos contextos específicos, de 'estrategias evidenciales' (Aikhenvald, 2004). En este trabajo, me ocuparé de algunos empleos específicos de ciertos tiempos verbales en español que, al igual que determinadas estructuras sintácticas, ciertas construcciones adverbiales, algunos marcadores del discurso, etc., pueden manifestar este tipo de significados. ${ }^{3}$ Más específicamente, buscaré demostrar que ciertos empleos 'dislocados' o 'no rectos' (Rojo, 1974; Rojo \& Veiga, 1999) del futuro (morfológico y perifrástico), del condicional (periodístico y científico) y del imperfecto, como los que se ejemplifican en (1) a (5) vehiculizan 'puntos de vista evidenciales citativos'.

1. No se resignaba a que la viuda lo plantara por ese enano repelente y bullidor que la seguía a todas partes como si fuera su doncella, con los codos doblados para que todos pudieran admirar la finura de sus sortijas. En su defensa, el señor Palacios hubiera podido responder, muy bien, yo seré todo eso, pero también soy más si sumamos las tierras que poseo, si contamos las cabezas de ganado mayor y si pesamos el grano de mis cosechas, y sobre todo, si nos pasamos por el banco para ver el color de los metales que allí guardo.(CREA. Colombia. Sánchez, H., El héroe de la familia. Bogotá, Tercer Mundo Editores, 1988).

2. Ma qué va a estar viendo jugadores! Está calculando los billetes que les va a chorear a los turcos estos. (Diario Olé, 6 de junio de 2011. Comentario de Pepe a la nota periodística "Maradona estuvo en la cancha viendo a los jugadores que va a dirigir". Disponible en https://www.ole.com.ar/futbol-internacional/veoveo-ves_0_B1Ty9nko3e.html)

3. La suba en el precio de los servicios habría originado el aumento de expensas impagas. [titular]

Según la Cámara de Administradores de Consorcios la mayoría de los inquilinos y propietarios que tienen deuda no pueden hacer frente a todas las erogaciones 
y para no sufrir cortes de luz o gas prefieren pagar las expensas "cuando pueden”. (El Dia, 28 marzo 2017. Disponible en https://www.eldia.com/nota/2017-3-28-10-10-13--el-aumento-en-losservicios-habria-originado-el-aumento-de-las-expensas-impagas)

4. El éxito de la hipótesis de la defectividad temporal del subjuntivo, debida a Picallo (1985/1990), es en parte responsable del poco interés dedicado a los tiempos del subjuntivo en gramática formal. En su forma original, esta hipótesis plantea que las cláusulas subjuntivas carecen de un tiempo independiente referencial especificado en la posición $\mathrm{T}(\mathrm{ense})$. Esta carencia explicaría la dificultad de tener subjuntivos en oraciones independientes y las reglas estrictas de correspondencia temporal a las que se supone estarían sometidas las subordinadas subjuntivas. (Laca, B., "Subjuntivo y concordancia temporal: hacia una estructura de la variación”).

5. - ¿Qué sabes de Juan?

- Llegaba el martes. (Ejemplo extraído de Leonetti \& Escandell Vidal, 2003: 135)

Para dar cuenta de este tipo de significados citativos, propondré una caracterización de la evidencialidad a la luz del Enfoque dialógico de la argumentación y de la polifonía (García Negroni, 2016, 2018a, 2018b, 2019; García Negroni \& Libenson, 2019, 2020a, 2020b, 2020c; García Negroni \& Hall, 2020). No centraré así la descripción del sentido comunicado en cómo o de dónde un sujeto hablante real habría obtenido el conocimiento de lo que afirma -como habitualmente se propone en los estudios sobre evidencialidad-, sino en cómo los puntos de vista evidenciales contribuyen a la representación dialógica y polifónico-argumentativa que el enunciado brinda de su propia enunciación. De acuerdo con la hipótesis que defenderé, los puntos de vista evidenciales citativos vehiculizados por los usos dislocados de los futuros, condicionales e imperfecto del tipo de los ejemplificados en (1) a (5) exigen recuperar 'marcos de discurso' previos que se muestran como la 'causa evidencial' de la enunciación en la que esos puntos de vista se expresan y frente a los cuales queda constituido un determinado posicionamiento subjetivo de respuesta. ${ }^{4}$

En lo que sigue, tras una breve presentación de los fundamentos teóricos y metodológicos del Enfoque dialógico de la argumentación y la polifonía en el que se inscribe mi investigación (sección 1), propongo una descripción dialógicoargumentativa de los empleos citativos del futuro (morfológico y perifrástico), del condicional (periodístico y científico) y del imperfecto. En todos los casos, describo los marcos de discurso que la enunciación obliga a recuperar como su causa y analizo los distintos posicionamientos subjetivos que, en respuesta a esos marcos, quedan plasmados en el enunciado (sección 2). En la última sección, retomo a modo de cierre las principales conclusiones que se derivan de la investigación. 


\section{Marco teórico-metodológico}

El análisis semántico que propone el Enfoque dialógico de la argumentación y la polifonía (de aquí en más, EDAP) mantiene el principio ducrotiano según el cual el sentido de nuestras palabras, expresiones o enunciados no está constituido por las cosas, los hechos o las propiedades que denotan, ni por los pensamientos o las creencias que sugieren, sino por los encadenamientos o discursos argumentativos que esas palabras, expresiones o enunciados evocan. Siguiendo a Ducrot (2004) y a Carel y Ducrot (2005), el EDAP sostiene que esos discursos argumentativos pueden ser normativos o transgresivos. En el primer caso, el encadenamiento aparece articulado por conectores conclusivos del tipo de 'por lo tanto', 'si... entonces', 'porque', 'en consecuencia', 'así que', etc. (realizaciones de un conector abstracto por lo tanto, abreviado como PLT); en el segundo, por conectores concesivos del tipo de 'sin embargo', 'a pesar de que', 'aunque', 'aun si', etc. (realizaciones de un conector abstracto sin embargo, abreviado como SE). Ahora bien, dos son los modos según los cuales una entidad lingǘstica -palabra o enunciado- puede evocar los encadenamientos que constituyen su sentido. Según señalan Carel y Ducrot (2005), esos dos modos son su argumentación externa (AE) y su argumentación interna (AI). $\mathrm{La} \mathrm{AE}$ refiere a los discursos argumentativos, tanto normativos como transgresivos, en los que la entidad interviene en tanto primer o segundo segmento. Las AE siempre van de a pares, esto es, si una entidad e tiene entre sus AE la argumentación 'e CONECTOR X', también tendrá entre sus AE la argumentación conversa, en la que el conector ha sido reemplazado por el otro (PLT por SE y viceversa) seguido de negación. Y ello es así porque en ambas argumentaciones se mantiene la misma interdependencia semántica entre los segmentos articulados. Por su parte, la AI se relaciona con los discursos argumentativos -en este caso, normativos 'o' transgresivos- en los que la entidad lingüística no interviene y que constituyen una especie de paráfrasis de dicha entidad. Para ejemplificar ambos tipos de argumentaciones, considérese el enunciado 'Aunque llovía, salió'. Entre las argumentaciones que constituyen su sentido se encuentran, entre otras, las siguientes AE a la derecha:

Aunque llovía, salió PLT pudo encontrarse con Juana.

Aunque llovía, salió SE no pudo encontrarse con Juana.

Aunque llovía, salió PLT a esa hora no estaba en su casa.

Aunque llovía, salió SE a esa hora estaba en su casa.

$\mathrm{Y}$, entre otras, las siguientes $\mathrm{AE}$ a la izquierda:

Tenía que hacer las compras PLT aunque llovía, salió.

No tenía que hacer las compras SE aunque llovía, salió.

Todavía tenía tiempo SE aunque llovía, salió. 
No tenía más tiempo PLT aunque llovía, salió.

Además de estas AE (a la derecha y a la izquierda), forma parte del sentido del enunciado tomado en consideración la siguiente AI:

Iluvia SE salir

Se observará que no ocurre lo mismo con la siguiente argumentación, en la que el conector abstracto SE ha sido remplazado por PLT seguido de negación:

Iluvia PLT Neg. salir

En efecto, a diferencia de las AE (que, como se indicó más arriba, van de a pares), las AI son o bien en PLT o bien en SE. Así, si 'lluvia SE salir' constituye la AI de 'Aunque llovía, salió', la argumentación 'lluvia PLT Neg. salir' no forma parte de su significación (i.e., no constituye su AI), sino de la de otro enunciado, a saber:

\section{Como llovía, no salió.}

Además de estas herramientas procedentes de la semántica argumentativa, el EDAP también hace suya la concepción polifónica y no intencionalista del sentido, por lo que, siguiendo a Ducrot $(1984,2001)$, asume que los diversos puntos de vista que se expresan a través de la enunciación no tienen por qué ser atribuidos a un mismo y único sujeto. También mantiene la distinción entre locutor L y locutor $\lambda$ : L (o locutor en tanto tal) es el ser de discurso que en el sentido del enunciado es presentado como su responsable y $\lambda$ (o locutor en tanto ser del mundo) es aquel a quien remiten las marcas de primera persona y de quien se habla en el enunciado que contiene dichas marcas. El EDAP cuestiona, en cambio, la concepción de L como una suerte de titiritero que, deliberada y conscientemente, pondría en escena distintos enunciadores. También rechaza el concepto de enunciador como origen de los contenidos vehiculizados en el enunciado y la idea de que, frente a los enunciadores, $\mathrm{L}$ tendría distintas actitudes. Para evitar el sesgo psicologicista que se desprende de estas caracterizaciones y para dar cuenta de las perspectivas semánticas que quedan plasmadas en el discurso, el EDAP adopta la noción de 'punto de vista' (de aquí en más, PdV) y propone la de 'posicionamiento subjetivo'.

Finalmente, el EDAP aboga por incorporar como parte de la descripción polifónico-argumentativa los aspectos dialógicos del sentido (Bajtín, 1981, 1982), es decir aquellos relacionados tanto con la inscripción del enunciado en la cadena discursiva como con el consecuente posicionamiento subjetivo de respuesta y de anticipación que queda en él configurado. Así, al concebir el enunciado en tanto eslabón en la cadena discursiva (Bajtín, 1982), el EDAP analiza los diferentes posicionamientos subjetivos que se manifiestan argumentativamente en el discurso como respuestas siempre dialógicas frente a los 'marcos de discurso' (de aquí en más, 
MD) que se presentan como la 'causa' de la enunciación (García Negroni, 2016, 2018a, 2019; García Negroni \& Libenson, 2020a, 2020b, 2020c). En tanto imagen que el enunciado brinda de su causa, los MD, que las instrucciones dialógico-causales exigen identificar, ${ }^{5}$ también deben ser descriptos - sostiene el EDAP - en términos de encadenamientos argumentativos. Otro tanto resulta necesario para dar cuenta de la relación dialógica entre dicha causa y el posicionamiento subjetivo que se manifiesta en la enunciación.

A la luz de estos presupuestos teóricos, en lo que sigue, trataré de dar cuenta de cómo los $\mathrm{PdV}$ evidenciales citativos vehiculizados por cada uno de los empleos 'dislocados' o 'no rectos' (Rojo \& Veiga, 1999) de los futuros, condicionales e imperfecto ejemplificados en la Introducción ponen de manifiesto la relación dialógico-argumentativa del enunciado con los otros en la cadena.

Para ello, mostraré que, en tanto PdV citativos, ellos comportan instrucciones dialógico-causales que obligan a identificar la causa de la enunciación en la que se expresan en un MD constituido por encadenamientos argumentativos en los que una determinada representación discursiva de un decir evocado queda articulada normativa o transgresivamente con distintas aserciones de $\lambda$ respecto de ese decir. Dicho de otro modo, según argumentaré, forma parte del sentido de las enunciaciones con los usos dislocados de los tiempos ejemplificados en (1) a (5) reconocer que ellas surgen, según el caso, en respuesta a los siguientes MD (los represento entre corchetes):

[Dicen/dijeron/se dice X PLT admito $(\lambda)$ que X es posible];

$[$ Dicen/dijeron/se dice X SE no estoy de acuerdo $(\lambda)$ con $\mathrm{X}]$;

[Se dice X SE no pude $(\lambda)$ corroborar $\mathrm{X}$;

[A dijo X PLT todos (incluido $\lambda$ ) en el campo disciplinario sabemos que $\mathrm{X}$ ha sido dicho por A];

[A me dijo X PLT creo $(\lambda)$ que X es asi];

$[\mathrm{Me}$ dijiste X SE no recuerdo $(\lambda) \mathrm{X}]$.

Sostendré, asimismo, que también forma parte del sentido de las enunciaciones que nos ocupan la determinación de los posicionamientos subjetivos de L surgidos en respuesta dialógica a estos diferentes $\mathrm{MD}$ que deben recuperarse como la causa evidencial del habla. Tanto los MD fundantes como las argumentaciones (externas e internas) evocadas en las respuestas serán las que darán cuenta de las propiedades que, en cada caso, reviste la enunciación (enunciación concesiva, refutativa, precavida y resguardada, distanciada, confiada pero prudente, de pedido cortés de rememoración). La enunciación responsiva, a su vez, brindará una imagen del decir evocado (como un decir plausible pero solo en parte acertado y justificado, como algo inadmisible, como un rumor que todavía no puede darse por cierto, como un decir calificado o como un decir confiable). 
El análisis que sigue es cualitativo y se basa en un corpus de enunciados auténticos tomados del Corpus de Referencia del Español Actual (CREA), de textos periodísticos disponibles en la web y de textos científicos del área de lingüística o de análisis del discurso. En el caso de los empleos del imperfecto citativo, se retoman los ejemplos analizados en la bibliografía especializada.

\section{Discusión y resultados}

\subsection{Futuros y PdV citativos: Acerca del futuro citativo y del futuro refutativo}

Aunque el futuro morfológico (FM) y el futuro perifrástico (FP) permiten la expresión de la 'futuridad' y pueden, por lo tanto, alternar (aunque, por cierto, con matices de significado distintos), la conmutación de una forma por otra no siempre resulta posible.

Así ocurre en los empleos 'no rectos' o 'dislocados', como los de (1) y (2), tal cual lo muestran las versiones (1a) y (2a), que no constituyen sus paráfrasis.

1. a. *Yo voy a ser todo eso, pero también soy más si sumamos las tierras que poseo, si contamos las cabezas de ganado mayor y si pesamos el grano de mis cosechas, y sobre todo, si nos pasamos por el banco...

2. a. *Ma qué estará viendo jugadores! Está calculando los billetes que les va a chorear a los turcos estos.

En la bibliografía especializada sobre el tema, estos empleos específicos del FM y FP, que aluden a hechos inscriptos en un presente actual o descriptivo, no han sido en general considerados ni diferenciados de otros usos no rectos. Así, para Rojo (1974: 114), la acción indicada por el FM dislocado siempre "posee una connotación de probabilidad o posibilidad que pertenece indudablemente a una esfera no temporal". Gennari (2002), por su parte, señala que la interpretación modal inferencial o probabilística habilitada, en ciertos contextos específicos, por el FM debe relacionarse con la aktionsart o modo de acción de la predicación. Según la autora, las predicaciones estativas (por ejemplo, Juan estará ahora en su casa) generan, a diferencia de las eventivas (por ejemplo, Juan leerá el libro), lecturas solapadas porque disparan una implicación pragmática temporal ('implicación de superintervalo'): si una predicación estativa se da en un intervalo $i$, puede inferirse que ella se dio en un tiempo previo a $i$ y que también seguirá dándose en un tiempo posterior a $i$. Y por esta implicación, cuando el momento de la enunciación y el intervalo se solapan, la lectura temporal del FM queda bloqueada y es la modal la única habilitada. En línea con Gennari (2002), Soto (2008), que analiza el morfema -ré ya como operador temporal, ya como operador modal epistémico subjetivo, hace notar que la lectura modal no se restringe solo a las predicaciones estativas. También es posible en las predicaciones dinámicas 
siempre y cuando estas contengan el rasgo semántico de duración e incluyan el momento del habla. En términos de Gennari (2008: 199), la lectura modal excluyente surge en predicaciones estativas o "en predicaciones dinámicas durativas en tanto la información contextual deje en claro que estas refieren a estados de cosas en curso". Tal el caso, por ejemplo, del FM 'irá' en el diálogo 'A: ¿Dónde va Juana?' 'B: Irá a su casa', en el que, como señala Soto (2008), la lectura de futuro queda bloqueada por cuanto el momento de habla está incluido en el tiempo de la predicación.

Bermúdez (2005a), por su parte, propone considerar que el valor modal deóntico que el FM tuvo en su origen (cf. gramaticalización de la perífrasis verbal latina amare habeo) dio lugar a su significado modal epistémico (como evaluación de la potencialidad o predictibilidad de un evento) al que luego se sumó el significado evidencial. ${ }^{6}$ El autor explica así, por un lado, la 'futuridad' señalada por el FM en enunciados del tipo 'Los beneficios que nos traerá esta ley son evidentes' y, por el otro, el significado del FM cuando refiere a eventos presentes o pasados, como en 'Estará cansado' o 'Se habrá perdido en la mudanza'. En el primer caso, según Bermúdez (2005a), el FM 'traerá' instaura una calificación modal epistémica; en el segundo, los FM 'estará' y ‘se habrá perdido' constituyen futuros evidenciales con el significado de inferencia a partir de una evidencia indirecta. Escandell Vidal (2010) va más allá y propone un enfoque unificado de la semántica del futuro basado exclusivamente en la noción de evidencialidad. Para la autora, el FM no codifica nunca información de tipo temporal ni indica que el acontecimiento pertenezca al área modal de la posibilidad. Antes bien, en todos sus usos discursivos, en la semántica del FM, estaría codificado que la fuente es el hablante y que su modo de acceso es indirecto e inferencial. González Vázquez (2016: 63) propone, en cambio, que el FM puede tener valor evidencial citativo, pero solo en "aquellos casos en los que no se puede adjudicar la fuente de información al interlocutor que acaba de mencionar explícitamente la proposición que recoge el futuro".

En relación con los empleos del FP que aquí nos ocupan, Cartagena (1999: 2968) solo menciona que se trata de un 'futuro replicativo' especializado "en rechazar una afirmación o suposición previa mediante una pregunta retórica enfática o una exclamación”. En su capítulo en la GDLE sobre las perífrasis verbales, Gómez Torrego (1999: 3370-3371) indica simplemente que, en oraciones exclamativointerrogativas, 'ir+a+infinitivo' permite enfatizar una afirmación o negación, "destacando lo necio o lo inoportuno de una pregunta o afirmación" o "la obviedad de lo que la otra persona pregunta". Escandell Vidal (2010: 29) alude también de manera breve al FP y afirma que, de modo análogo al FM, la perífrasis tampoco tendría "la localización temporal de los eventos en el porvenir como parte de su significado básico, sino que [adquiriría] inferencialmente sus valores prospectivos". Finalmente, Kornfeld (2014) caracteriza este tipo de empleos como epistémicos, derivados de preguntas retóricas en las que el pronombre interrogativo 'qué' cumple la 
función exclusiva de 'rechazar enfáticamente' una proposición previa a la que 'se descalifica por absurda o ilógica’.

Siguiendo lo planteado en García Negroni (2016), aquí argumentaré que los empleos de FM y FP del tipo de los ejemplificados en (1) y (2) codifican diferentes tipos de PdV evidenciales citativos, los que habilitan dos escenas enunciativas claramente diversas: una escena concesiva, en el caso del FM; una escena refutativa, en el del FP. Consideremos en primer lugar el caso del FM y la escena concesiva asociada (cf. (1), que reitero, (6) y (7)):

1. No se resignaba a que la viuda lo plantara por ese enano repelente y bullidor que la seguía a todas partes como si fuera su doncella, con los codos doblados para que todos pudieran admirar la finura de sus sortijas. En su defensa, el señor Palacios hubiera podido responder, muy bien, yo seré todo eso, pero también soy más si sumamos las tierras que poseo, si contamos las cabezas de ganado mayor y si pesamos el grano de mis cosechas, y sobre todo, si nos pasamos por el banco para ver el color de los metales que allí guardo.(CREA. Colombia. Sánchez, H., El héroe de la familia. Bogotá, Tercer Mundo Editores, 1988).

6. No seré feliz, pero tengo marido (título de la obra de teatro de V. Gómez Thorpe)

7. Esta noble señora tendrá mucha plata, pero la cara se la han dejado hecha unos zorros los cirujanos. (Libertaddigital, 20 de febrero de 2014. Comentario a la nota "La duquesa de Alba podría ser la reina de Escocia". Disponible en https:// www.libertaddigital.com/chic/corazon/2014-02-20/la-duquesa-dealba-podria-ser-la-reina-de-escocia-1276511223/)

En tanto PdV evidenciales, los futuros 'seré' y 'tendrá' presentes en (1), (6) y (7) instan a recuperar un MD citativo referido a discursos ajenos previos (en (1), el de aquellos que critican al señor Palacios; en (6), el de las amigas, de la madre o de otras personas que sostienen o pudieron haber sostenido que $\lambda$ no es feliz; en (7), el de cierta sabiduría popular según la cual la duquesa de Alba tiene mucho dinero) que $\lambda$, la representación discursiva del locutor en tanto ser del mundo, admite como posibles:

[Dicen/dijeron/se dice X PLT admito $(\lambda)$ que X es posible]

$\mathrm{Y}$ es precisamente a ese $\mathrm{MD}$ al que la enunciación a cargo de $\mathrm{L}$ responde con un posicionamiento de concesión o aceptación momentánea. ${ }^{7}$ Represento ese posicionamiento subjetivo de respuesta en itálicas y el vínculo que queda establecido entre el MD fundante y la enunciación desencadenada a partir de él mediante un POR LO TANTO dialógico.

[Dicen/dijeron/se dice X PLT admito ( $\lambda$ ) que X es posible] 


\section{POR LO TANTO}

\section{Enunciación concesiva de $\mathrm{L}$}

Dicho en términos menos formales, la relación dialógica que, por la presencia de los PdV evidenciales originados en los FM, queda establecida entre el posicionamiento subjetivo que emerge en (1), (6) y (7) y la causa evidencial citativa que desencadena, en cada caso, la enunciación puede glosarse como sigue:

[como admito ( $\lambda$ que $\mathrm{X}$ (eso que dicen los que critican al señor Palacios//eso que $\mathrm{mi}$ madre/mis amigas/otros dicen//eso que se dice) es posible], el posicionamiento subjetivo (L) es de aceptación momentánea del decir ajeno.

Ahora bien, si en el MD que desencadena la enunciación, $\lambda$ admite que $\mathrm{X}$ es posible, ha de verse que el posicionamiento de respuesta de L solo concierne la AI, y no las AE, que, en cada caso, constituyen el sentido de ese decir ajeno evocado ${ }^{8}$.

En efecto, si en (1) se mantienen las AI relativas a los rasgos negativos que se atribuyen del señor Palacios (i.e., su prontitud para servir a la viuda, o su jactancia y ostentación); y en (6) y (7), las que definen, respectivamente, el sentido de 'no ser feliz' y de 'tener mucha plata' (cf. 1a, 6a, 7a):

1. a. ser bullidor PLT seguir a la viuda por todas partes $/ / \lambda$ mostrar sortijas PLT querer ser admirado

6. a. carencias o dificultades espirituales PLT no satisfacción espiritual

7. a. riqueza PLT abundancia de bienes

no ocurre lo mismo con las AE, que sí forman parte, en cambio, del sentido de (8), (9) y (10), que siguen, y en los que las formas de FM han sido reemplazadas por las de presente 'eres', 'sos' y 'tiene':

8. Eres un enano bullidor que la sigues a todas partes como si fuera su doncella, con los codos doblados para que todos puedan admirar la finura de tus sortijas.

9. No sos feliz.

10. Esta noble señora tiene mucha plata.

Susceptibles de ser considerados como los discursos previos $\mathrm{X}$ evocados en los $\mathrm{MD}$ a los que responden las enunciaciones con FM, (8), (9) y (10) admiten, en efecto, entre otras las siguientes AE:

8a. Eres un enano bullidor que la sigues a todas partes como si fueras su doncella, con los codos doblados para que todos puedan admirar la finura de tus sortijas PLT eres insoportable.

9. a. No sos feliz PLT sos digna de compasión.

10. a. Esta noble señora tiene mucha plata PLT puede comprarse lo que quiera. 
Este no es el caso de (1), (6) y (7), en los que dichas AE no quedan retomadas en la continuidad discursiva. Antes bien, las AE que primarán en el discurso serán las asociadas a los segmentos que continúan a 'pero' (i. e., las relativas al poderío económico del señor Palacios, en (1); las relacionadas con el hecho de tener marido, en (6); las referidas al mal resultado de las operaciones faciales a las que la duquesa fue sometida en (7)). Y es esto, precisamente, lo que explica el posicionamiento concesivo que se manifiesta en estas enunciaciones.

Pero hay más, ese posicionamiento concesivo no solo da cuenta de un sujeto que toma a su cargo las AI, pero no las AE, del discurso X evocado en el MD citativo que debe recuperarse como la causa de la enunciación. En tanto respuesta dialógica, la enunciación brinda además una imagen de ese discurso evocado como algo plausible y atendible, pero solo en parte acertado y justificado.

Detengámonos ahora en el caso del FP y en la escena refutativa asociada:

2. Ma qué va a estar viendo jugadores! Está calculando los billetes que les va a chorear a los turcos estos. (Diario Olé, 6 de junio de 2011. Comentario de Pepe a la nota periodística "Maradona estuvo en la cancha viendo a los jugadores que va a dirigir")

11. Me cuesta creer qué mal se acostumbraron estas empresas, que se sientan a negociar pidiendo aumentos del 60\% en el agua. ¡Minga que les vamos a aumentar! Primero que le den agua al pueblo". (La Nación, Kirchner advirtió a Aguas Argentinas, 28/1/2005. Disponible en: www.lanacion.com.ar/politica/kirchner-advirtio-a-aguas-argentinas$\underline{\operatorname{nid} 674796 /)}$

En combinación con marcadores de discurso refutativos del tipo de 'ma qué, 'minga que', 'y todo', 'mira si, ${ }^{9}$ el FP exige, en estos casos, recuperar un MD previo que involucra la representación de un discurso ajeno que, esta vez, queda articulado con una aserción sobre el desacuerdo de $\lambda$ respecto de él. Y es ello lo que explica el posicionamiento subjetivo de refutación que surge en respuesta a ese MD:

[Dicen/dijeron/se dice X SE no estoy de acuerdo $(\lambda)$ con X]

\section{POR LO TANTO}

Enunciación refutativa de $L$

En otras palabras, la relación dialógica entre (2) y (11) y la causa evidencial citativa que desencadena en cada caso la enunciación puede glosarse como sigue:

[como, a pesar de que $\mathrm{X}$ fue dicho (lo que dice la nota periodística sobre Maradona / eso que dicen las empresas), no estoy de acuerdo $(\lambda)$ con $\mathrm{X}]$, el posicionamiento subjetivo (L) es de rechazo vigoroso del decir ajeno. 
$\mathrm{Y}$ en esa refutación, $\mathrm{L}$ rechaza no solo las AE de los encadenamientos evocados por el discurso $\mathrm{X}$ ajeno, entre otras:

AE de X (2): ver a los jugadores que va a dirigir PLT estar feliz ser Maradona PLT ver a los jugadores que va a dirigir

AE de X (11): tener derechos PLT pedir aumento de tarifas pedir aumento de tarifas PLT lograr mayor rentabilidad

sino también las AI correspondientes. Así, si los discursos X evocados en el MD (en (2), 'Maradona estuvo en la cancha viendo a los jugadores que va a dirigir'; y en (11), 'El Estado debe darnos el aumento del 60\% que queremos') tienen como AI

AI de X en el $M D$ fundante de (2): análisis de jugadores PLT entrenador serio AI de X en el MD fundante de (11): empresas con poder PLT empresas deciden políticas estatales

ha de verse que, tal como lo ponen en evidencia las continuaciones en cada caso (en (2), 'Está calculando los billetes que les va a chorear a los turcos estos'; y en (8), 'Primero que le den agua al pueblo'), dichas AI son rechazadas y sustituidas por las siguientes AI:

AI (rectificativa de (2)): cálculo de billetes PLT codicia

AI (rectificativa de (11)): Estado con poder PLT Estado decide políticas estatales

Dicho de otro modo, en las enunciaciones refutativas (2) y (11), la caracterización de Maradona como entrenador-responsable-que-analiza-a-los-jugadores y la de las empresas-poderosas-que-deciden-la-política-del-Estado quedan descalificadas y, en su lugar, se plantean como las AI que corresponden la del codicioso-que-cuenta-el-dinero y la del Estado-poderoso-que-determina-lo-que-se-debe-hacer.

En suma, en este tipo de enunciaciones, el PdV evidencial citativo materializado por el FP insta a recuperar un MD citativo al que la enunciación responde con una refutación seguida de una rectificación que reemplaza una representación argumentativa de la situación por otra bien diferente. Y en esa refutación, la enunciación brinda una imagen del decir evocado en el MD como algo inadmisible y errado que debe ser sustituido.

\subsection{Condicionales y PdV citativos: Acerca del condicional periodístico $y$ del condicional científico}

Característico de los medios de comunicación, el condicional periodístico -también llamado condicional de rumor-, ha sido objeto de numerosos estudios. Reyes (1994) lo analiza como evidencial citativo. Vatrican (2014: 264) señala que este condicional "da a entender que el hablante cita, esto es, reproduce lo que alguien le ha dicho, sin 
asegurar que sea verdad". Para Kronning (2015: 507-508), se trata del condicional epistémico de atribución, al que caracteriza como:

"un marcador gramatical mixto, que expresa a un tiempo la modalización cero -que indica la negativa del hablante a hacerse cargo del contenido cognitivo de su enunciado- y un tipo particular de mediación epistémica (o evidencialidad), a saber: la atribución de dicho contenido a una fuente externa".

En esta misma línea, Bermúdez (2016: 50) describe el condicional de rumor como marcador de información de tercera mano ("alguien dice que alguien dice [que alguien dice...] X"), que indica la renuncia del hablante "a hacerse cargo de la veracidad de la información expresada, al mismo tiempo que no la pone en duda".

Por mi parte, y a la luz de los presupuestos teóricos del EDAP, sostengo que el condicional periodístico (CP) vehiculiza un PdV evidencial citativo que, en tanto tal, insta a ver la enunciación en la que aparece como suscitada por un MD al que la enunciación responde precavidamente. Consideremos el caso de 'habría originado' en el titular de la nota periodística de (3), que reitero, y de 'habría muerto ahogado' y 'habría permanecido' en el titular de la nota de (12).

3. La suba en el precio de los servicios habría originado el aumento de expensas impagas [titular]

Según la Cámara de Administradores de Consorcios la mayoría de los inquilinos y propietarios que tienen deuda no pueden hacer frente a todas las erogaciones y para no sufrir cortes de luz o gas prefieren pagar las expensas “cuando pueden". (El Día 28 marzo 2017)

12. Maldonado habría muerto ahogado y su cuerpo habría permanecido dos meses en el agua [titular]

Buenos Aires, 22 de Oct. (Notimérica). Tras una autopsia larga y minuciosa, en la que participaron más de 50 expertos, los forenses del Cuerpo Médico Forense (CMF) de la Corte han determinado que Santiago Maldonado no murió por lesiones provocadas por terceros. (Disponible en https://www.notimerica.com/sociedad/noticia-santiago-maldonado-habria-muertoahogado-permanecido-menos-dos-meses-agua-20171022092126.html)

Según mi hipótesis, la presencia de los PdV citativos desplegados por los CP en (3) y (12) exige recuperar un MD del tipo:

[Se dice X SE no pude $(\lambda)$ corroborar X]

Estos diferentes elementos de sentido (i. e., esos discursos argumentativos previos atribuidos, tal como se indica luego en el texto, a la Cámara de Administradores de Consorcios (en 3) y al Cuerpo Médico Forense (en 12), ${ }^{10}$ que $\lambda$ no ha podido 
corroborar) explican la actitud de prudencia y de reserva que se manifiesta en la respuesta de L, que no hace del decir rememorado el objeto declarado de su propia enunciación. Así lo explicitan las glosas que siguen:

3. a. [como, a pesar de que se dice $X$, no pude $(\lambda)$ corroborar $X]$, afirmo con prudencia que la suba en el precio originó el aumento de las expensas impagas.

12. a. [como, a pesar de que se dice $X$, no pude $(\lambda)$ corroborar $X$ ], afirmo con prudencia que Santiago Maldonado murió ahogado y que su cuerpo permaneció en el agua por dos meses.

En otras palabras, en (3) y (12), por las instrucciones dialógico-causales asociadas al PdV evidencial, la imagen que el enunciado brinda de su propia enunciación es la de un habla causada por un rumor, esto es, por un decir ajeno que L (el ser de discurso responsable de la enunciación periodística) retoma pero que no asume por su cuenta porque $\lambda$ (la representación discursiva del individuo que era y que es fuera de su enunciación) no pudo corroborarlo ni confirmarlo. $\mathrm{Y}$ es esta calificación de la enunciación por su causa, que forma parte del sentido del enunciado, la que da cuenta de la enunciación resguardada y precavida que se manifiesta en (3) y en (12). Como bien señala Vatrican (2014: 266), en relación con la modalidad epistémica, el CP "funciona como operador epistémico que no opera sobre el enunciado -como en el caso del condicional de conjetura- sino sobre la enunciación”.

[Se dice X SE no pude $(\lambda)$ corroborar $\mathrm{X}$ ]

\section{POR LO TANTO}

\section{Enunciación precavida y resguardada de $L^{11}$}

Diferente sería el caso si, en lugar de 'habría originado' o de 'habría muerto ahogado', hubiese aparecido el pretérito perfecto simple de indicativo, el que, al no vehiculizar un PdV evidencial, no contiene instrucciones que exijan identificar un MD previo citativo como la causa de la enunciación.

13. La suba en el precio de los servicios originó el aumento de expensas impagas.

14. Santiago Maldonado murió ahogado.

En efecto, presentada por 'originó' o por 'murió' como motivada por una convicción propia del sujeto que elegiría comunicar esa información a propósito de la situación, la imagen de la enunciación que proponen (13) y (14) es la de un L que se hace garante del $\mathrm{PdV}$ relativo a la relación causal entre aumento de servicios y no pago de expensas, en (13), y del PdV que muestra la relación normativa entre muerte por ahogamiento y muerte accidental, en (14), y con los que, por lo tanto, queda fuertemente comprometido. 


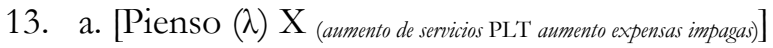
POR LO TANTO

Enunciación asertiva y comprometida de $\mathrm{L}$

14. a. $[$ Pienso $(\lambda) \mathrm{X}$ (muerte por abogamiento PLT muerte accidenta) $]$ POR LO TANTO

Enunciación asertiva y comprometida de $\mathrm{L}$

De hecho, si luego de la enunciación de estos enunciados, se determinara que tales relaciones no eran ciertas, solo al autor de (13) y de (14) -y no al de (3) y (12)- podría reprochársele el haber mentido, inventado o inducido a error.

Se observará, no obstante, que si las enunciaciones de (3) y (12) son resguardadas y precavidas, ello no impide que estos enunciados argumenten en el mismo sentido que (13) y (14): ${ }^{12}$ como se observa en (15) y (16), tanto (3) como (13), podrían tener como posibles continuidades discursivas 'El Gobierno debe revisar su política de tarifas' (que constituye la $\mathrm{AE}$ a la derecha del primer segmento) o 'Los administradores de los consorcios están preocupado's (que constituye la AE a la derecha del segundo segmento). Y, como se observa en (17) y (18), tanto (12) como (14) podrían presentar, por ejemplo, como AE a la derecha 'El Gobierno está más tranquilo' o 'La familia está desolada'.

15. La suba en el precio de los servicios originól habría originado el aumento de expensas impagas, por lo que el Gobierno debe revisar su política de tarifas.

16. La suba en el precio de los servicios originó/habría originado el aumento de expensas impagas, por lo que los administradores de los consorcios están preocupados.

17. Santiago Maldonado murió/habría muerto ahogado. El Gobierno está más tranquilo.

18. Santiago Maldonado murió/ habría muerto ahogado. La familia está desolada.

Sin embargo, ha de verse que la presencia del PdV evidencial citativo en (3) y (12) restringe en parte la significación de la oraciones base (13) y (14), en pretérito perfecto simple de indicativo: a diferencia de (13), (3) no admite como su prolongación discursos reformulativos del tipo 'En efecto, la política tarifaria del gobierno impactó fuertemente en los bolsillos de propietarios e inquilinos', o explicativos, como 'Es que la política tarifaria del gobierno impactó fuertemente en los bolsillos de propietarios e inquilinos'.

19. La suba en el precio de los servicios originó el aumento de expensas impagas. En efecto, / Es que la política tarifaria del gobierno impactó fuertemente en los bolsillos de propietarios e inquilinos. 
20. *La suba en el precio de los servicios habría originado el aumento de expensas impagas. En efecto, / Es que la política tarifaria del gobierno impactó fuertemente en los bolsillos de propietarios e inquilinos.

De modo análogo, a diferencia de (14), (12) no admite como una continuación posible una consecutiva del tipo 'Queda descartado así que el Estado haya tenido alguna responsabilidad en dicha muerte / Queda descartado así que haya muerto por lesiones provocadas por terceros':

21. Santiago Maldonado murió ahogado. Queda descartado así que el Estado haya tenido alguna responsabilidad en dicha muerte / que haya muerto por lesiones provocadas por terceros.

22. *Santiago Maldonado habría muerto ahogado. Queda descartado así que el Estado haya tenido alguna responsabilidad en dicha muerte / que haya muerto por lesiones provocadas por terceros.

La imposibilidad de la reformulación introducida por 'en efecto' o de la explicación encabezada por 'Es que' en (20) pone en evidencia que, en (3), la relación causal entre aumento de servicios y no pago de expensas -que constituye la AI de la X evocada en el MD- no solo no es asumida por L (y ello como consecuencia de que la enunciación se muestra como desencadenada por discursos ajenos que $\lambda$ no pudo corroborar), sino que ella no constituye, como sí ocurre en (13), el objeto declarado de la enunciación. Dicho de otro modo, por la presencia del PdV evidencial plasmado en el CP, (3) evoca una parte y solo una parte de las argumentaciones evocadas por su alternativa en indicativo (13).

Análogamente, si (21) es posible, el contraste con (22) patentiza la restricción que el PdV evidencial citativo introduce en el significado de (14). En efecto, las consecutivas 'Queda descartada así la responsabilidad del Estado en dicha muerte/ Queda descartado así que haya muerto por lesiones provocadas por terceros' solo resultan posibles si la relación causal (muerte por ahogamiento PLT muerte accidental) sobre la que encadenan y que constituye la AI de (14) se presenta como asumida por L. No es este el caso de (12), en el que dicha AI no constituye el tema de la enunciación de L. Mostrada, esa relación causal aparece solo evocada en el MD que funda la enunciación bajo la forma de discursos de otros que $\lambda$ no ha podido corroborar o confirmar.

En suma, la enunciación precavida o resguardada que emerge en casos como los de (3) y (12) puede comprenderse como una reproducción con disociación enunciativa en la que se mantienen las AE de la X evocada en el MD, pero no su AI. Así, como en el $\mathrm{MD} \lambda$ queda representado como alguien que no pudo corroborar $\mathrm{X}$, en la enunciación responsiva, la AI solo aparece reproducida sin que ello implique que $\mathrm{L}$ reproductor se haga cargo de ella. 
[como, a pesar de que se dice $\mathrm{X}$, no pude $(\lambda)$ corroborar $\mathrm{X}$ ], el posicionamiento subjetivo (L) es de reproducción prudente con disociación enunciativa

$\mathrm{Y}$ es este posicionamiento de disociación enunciativa el que, a su vez, da cuenta de la imagen del decir evocado como un rumor, es decir como un decir que, aunque probable, todavía no puede darse por cierto.

Ahora bien, además del condicional propio del discurso periodístico, existe otro empleo citativo del condicional. Me refiero al condicional científico (CC) que con frecuencia aparece en los textos académicos y del que me ocuparé a continuación. Consideremos al respecto (4), que reitero, y (23)-(25), en los que en CC se refiere a hechos relativos al presente gnómico, característico de este tipo de discursos:

4. El éxito de la hipótesis de la defectividad temporal del subjuntivo, debida a Picallo (1985/1990), es en parte responsable del poco interés dedicado a los tiempos del subjuntivo en gramática formal. En su forma original, esta hipótesis plantea que las cláusulas subjuntivas carecen de un tiempo independiente referencial especificado en la posición T(ense). Esta carencia explicaría la dificultad de tener subjuntivos en oraciones independientes y las reglas estrictas de correspondencia temporal a las que se supone estarían sometidas las subordinadas subjuntivas. (Laca, B., "Subjuntivo y concordancia temporal: hacia una estructura de la variación")

23. Dentro de los estudios de pragmática, la Teoría de la Cortesía de P. Brown y S. Levinson (1987) proporciona algunos criterios útiles para afrontar el estudio de la censura como reacción a una amenaza. Estos autores proponen una fórmula que calcularía el peso de un mensaje como amenaza a la imagen social de un interlocutor (face-threateningacts [FTAs]). En esta fórmula se tienen en cuenta tres variables sociológicas: (...). Variemos ahora la ecuación para aproximarnos a una mejor descripción de la amenaza que constituye un mensaje para una ideología. (Portolés, J., "Evitar la censura: análisis pragmático")

24. Maingueneau enfatiza el hecho de que la enunciación adviene en un espacio instituido, definido por el género de discurso, y también en la dimensión constructiva de este discurso, que se pone en escena e instaura su propio espacio de enunciación. El ethos operaría como la figura de una convocatoria, por la cual el destinatario sería convocado a un lugar, inscripto en la instancia de enunciación que el propio discurso implica. (Dagatti, M., Ethos y gobernabilidad)

25. Para ello, partiendo de la existencia de categorías funcionales que completan las categorías léxicas, Speas y Tenny (2003) defienden la existencia de una proyección funcional especial vinculada con la manera del decir y que las autores denominan Speech Act Phrase (Sintagma de Acto de Habla). Dicha 
proyección ocuparía la posición más alta en la estructura de la oración y su cometido sería el de representar en la sintaxis la información pragmática contenida en todo acto de habla. (Rodríguez Ramalle, M.T., "Estudio sintáctico y discursivo de algunas estructuras enunciativas y citativas del español")

Según Bermúdez (2016), el CC se caracteriza por indicar que es producto de una elaboración cognitiva por parte del escritor del artículo. De allí que "la información expresada no es meramente una cita, sino más bien es una interpretación, una elaboración cognitiva de las palabras originales [del autor citado]" (Bermúdez, 2016: 58). En términos de Bermúdez (2016), el CC expresa información de segunda mano y modo de acceso cognitivo a la fuente de información, de modo que el hablante/escritor

si bien por un lado expresa la renuncia a hacerse cargo de la veracidad de la información presentada en el enunciado, (...) al mismo tiempo sí se hace cargo de la elaboración cognitiva realizada sobre el discurso atribuido. (Bermúdez, 2016: 62-63)

Como Bermúdez (2005a), considero que, al igual que las enunciaciones con CP, aquellas con CC también implican una cierta precaución o resguardo. Argumentaré, sin embargo, que, en el caso del CC, dicha reserva no deriva del hecho de que, como ocurre en el caso del CP, L reproductor se hace cargo de las AE pero no asume por su cuenta la AI de la X evocada en el MD fundante de la enunciación. Antes bien, la reserva que se manifiesta en las enunciaciones con CC debe leerse como una toma de distancia respecto de un decir ajeno que forma parte del campo disciplinario. ${ }^{13} \mathrm{En}$ efecto, tal como lo muestran (4) y (23)-(25), la imagen que estos enunciados brindan de la propia enunciación es la de un habla causada por un decir X autorizado (A es el autor de $\mathrm{X}$ ) que $\mathrm{L}$ reproduce, pero disociándose de él porque todos, incluido $\lambda$ (la representación discursiva del locutor que era y que es fuera de la enunciación en tanto miembro de la comunidad científica), sabemos/reconocemos que ese decir tiene una autoría y que el plagio es una práctica indebida. Y es esta calificación de la enunciación por su causa, que forma parte del sentido, la que da cuenta de la enunciación distanciada que se manifiesta en los enunciados con CC.

Dicho de otro modo, la presencia de los PdV citativos vehiculizados por el CC insta a recuperar como la causa de la enunciación en la que dichos PdV se expresan un MD del tipo

[A dijo X PLT todos (incluido $\lambda$ ) en el campo disciplinario sabemos que $\mathrm{X}$ ha sido dicho por A]

al que la enunciación responde con el distanciamiento que implica el reconocimiento enunciativo del decir ajeno: 


\section{POR LO TANTO}

\section{Enunciación de reproducción distanciada de $\mathrm{L}$}

Ahora bien, esta enunciación que reproduce con el debido reconocimiento el decir ajeno - tal como lo exigen las normas que rigen el discurso científico- no implica que, en ella, las AE y la AI de la X evocada en el MD queden confirmadas y asumidas como propias en la continuación del discurso. Así, si en casos como el de (24) y (25), el posicionamiento subjetivo de respuesta no constituye un cuestionamiento del PdV citativo introducido por el CC (de hecho, en ambos casos, el texto se inscribe en la misma línea teórica de los autores citados y continúa argumentativamente a partir de él), no sucede lo mismo en casos como los de (4) o (23). En efecto, en este tipo de empleos (por cierto muy frecuentes en los textos académicos), los PdV plasmados en los CC constituyen formas que, al tiempo que dan cuenta de la otredad enunciativa, preanuncian el desacuerdo y la argumentación contraria de L en la continuidad de su discurso. Así ocurre, por ejemplo en (4), en el que la enunciación con el PdV evidencial citativo vehiculizado por los CC 'explicaría' y 'estarían sometidas' insta a recuperar como su causa un MD referido a la hipótesis de la defectividad temporal del subjuntivo de Picallo con la que el responsable de la enunciación no acuerda. No solo se caracteriza dicha hipótesis como 'en parte responsable del poco interés dedicado a los tiempos de subjuntivo en gramática formal', sino que es esa hipótesis la que precisamente será discutida en el texto. Análogamente, en (23), el CC en 'calcularía', que preanuncia la divergencia, permite oponer a la fórmula de Brown y Levinson 'que 'calcularía' el peso de un mensaje como amenaza a la imagen social de un interlocutor', la ecuación que sí será adoptada en la continuidad discursiva para 'aproximarnos a una mejor descripción'.

Así, ya sea que responda al reconocimiento de una deuda intelectual para avanzar en la misma línea teórica (cf. (24) y (25)), ya sea que señale la alteridad enunciativa para dar lugar a un desacuerdo (cf. (4) y (23)), la enunciación con el CC da siempre cuenta del posicionamiento de reconocimiento enunciativo de un decir calificado y del consiguiente distanciamiento respecto de ese decir que, evocado en el MD, suscita la enunciación.

[como todos (incluido $\lambda$ ) en el campo disciplinario sabemos que $\mathrm{X}$ ha sido dicho por A], el posicionamiento subjetivo (L) es de reproducción distanciada por reconocimiento enunciativo.

En suma, motivados por el género discursivo en el que aparecen y, por consiguiente, diferentes en cada caso, los MD previos que el CP y el CC instan a recuperar como la causa de la enunciación en la que aparecen explican las diferencias de sentido que se derivan de las enunciaciones periodísticas y de las enunciaciones académicas. A su vez, el posicionamiento de reproducción distanciada presente en uno y otro tipo de respuesta dialógica da cuenta de las diferentes imágenes que surgen del 
decir ajeno: un rumor que, como tal, no puede darse por cierto, en un caso; un decir que, en tanto parte de un campo disciplinario, constituye un punto de partida calificado para argumentar a partir de él (ya sea en la misma línea, ya sea en líneas divergentes), en el otro.

\subsection{Pretérito Imperfecto y PdV citativo}

Según Reyes (1994), en una aserción como 'Mañana daba una conferencia María', el pretérito imperfecto con valor citativo (PIC) es utilizado para disociarse de la información transmitida:

"el hablante no asume enteramente lo que dice, y para eso indica (por ejemplo, usando el imperfecto de ese modo peculiar) que su conocimiento procede del testimonio de otro" (Reyes, 1994: 12).

En la misma línea, la RAE/AALE (2009: 445) afirma que el:

"llamado imperfecto citativo o de cita permite al hablante eludir la responsabilidad directa por sus palabras y presentarlas como información emitida por otros".

En cuanto a las restricciones específicas que disparan la interpretación citativa del pretérito imperfecto, Leonetti y Escandell Vidal (2003) señalan que dicha interpretación se correlaciona sistemáticamente con la ocurrencia de predicados télicos (en particular, realizaciones y logros) así como con lecturas prospectivas (que ubican el evento en un futuro con respecto a un punto de referencia pasado contextual) y con situaciones que deben concebirse como planificadas. En palabras de los autores,

"quotative readings of the IMPF arise as a particular effect of aspectual coercion: they occur when the IMPF coerces a telic predicate under its scope into an atelic one by producing a prospective reading." (Leonetti \& Escandell Vidal, 2003:141)

Por su parte, y aunque considera citativos empleos del imperfecto sin lectura prospectiva del tipo 'Repsol, que ayer pagaba dividendo, movió 23.984 millones de pesetas, y Fecsa, que lo paga hoy 6.310 millones de pesetas', El Mundo, 09/01/1996 ejemplo en el que, sin duda, cabe preguntarse acerca del valor citativo de 'pagaba'-, Hassler (2017) argumenta acerca del efecto de atenuación que produce el empleo de este tiempo en textos narrativos y periodísticos escritos. Así, según la autora, el empleo del PIC en el discurso periodístico:

"parece ser una estrategia pragmática-comunicativa de atenuación o mitigación" que le permite al periodista no indicar "de dónde proviene la información y no asumir así completamente la responsabilidad de tales enunciados” (Hassler, 2017: 31).

Ahora bien, si no caben dudas acerca del valor citativo que el pretérito imperfecto puede desarrollar en determinados contextos y del efecto de reserva o de atenuación 
respecto del contenido semántico que se comunica, estas caracterizaciones no permiten dar cuenta de las diferencias de sentido que existen entre las enunciaciones con PIC y aquellas con CP, de las que nos ocupamos más arriba. A continuación, propongo un análisis dialógico-argumentativo que busca precisamente dar cuenta de esa especificidad. Consideremos (5), que reitero, (26) y (27):

5. - ¿Qué sabes de Juan?

- Llegaba el martes. (Ejemplo extraído de Leonetti \& Escandell Vidal, 2003: 135)

26. -¿Qué tal sigue Ana?

-Mejor, me parece. No la vi, porque cuando llegué, dormía. Pero había comido algo y tenía menos fiebre. Esta noche, la veía el médico de nuevo. (Ejemplo extraído de Reyes, 1994: 31)

27. - Esta noche la daban de alta.(Ejemplo extraído de Leonetti \& Escandell Vidal, 2003: 138) ${ }^{14}$

De acuerdo con la hipótesis que guía mi trabajo, los PIC del tipo de los de (5), (26) y (27) vehiculizan PdV evidenciales citativos y, en tanto tales, exigen recuperar un MD que se presenta como la causa fundante de la enunciación que los contiene. En esta oportunidad, ese MD se relaciona con un discurso de alguien específico y relevante en el contexto que $\lambda$, la representación discursiva del locutor en tanto ser del mundo, cree o supone verdadero. $\mathrm{Y}$ es a este $\mathrm{MD}$ al que la enunciación responde con un posicionamiento subjetivo de reproducción confiada, pero prudente.

[A me dijo X PLT creo $(\lambda)$ que X es asi]

POR LO TANTO

Enunciación de reproducción confiada pero prudente de L

Ahora bien, ¿cómo se explica ese posicionamiento de reproducción confiada, pero prudente y cautelosa, si la enunciación surge en respuesta a un MD relativo a un decir de $A$ que $\lambda$ cree que es así? Para responder a esta pregunta, la comparación con el posicionamiento de reproducción resguardada y precavida que surge de las enunciaciones con CP puede resultar reveladora.

Como se recordará, las enunciaciones con CP restringen la significación del enunciado base en indicativo (pretérito perfecto simple, en el caso del condicional compuesto; presente o futuro, en el caso del condicional simple). Las enunciaciones con $\mathrm{CP}$, en efecto, conservan las mismas AE evocadas por la alternativa en presente (cf. (28)), pero no su AI (cf. la posibilidad de (29), pero no la de (30)). 
28. Mañana le darían / dan el alta. La familia está mucho más tranquila.

29. Mañana le dan el alta, lo que significa que mañana mismo podrá reincorporarse a su vida cotidiana.

30. ??Mañana le datían el alta, lo que significa que mañana mismo podrá reincorporarse a su vida cotidiana.

Este no es el caso de las enunciaciones con PIC. En efecto, en ellas, tanto las AE como la AI de la X evocada en el MD que debe recuperarse parecen mantenerse en la enunciación reproductora.

31. Mañana le daban el alta. La familia está mucho más tranquila.

32. Mañana le daban el alta, lo que significa que mañana mismo podrá reincorporarse a su vida cotidiana.

La reserva o cautela que se manifiesta en (5), (26) y (27) no se relaciona así con las argumentaciones evocadas por $\mathrm{X}$ que no se retoman en la enunciación reproductora, sino con la introducción por parte de L de una suerte de condición asociada a la incertidumbre de lo que puede suceder en el futuro. Así, en lugar de restringir la significación del enunciado base en presente o futuro de indicativo como ocurre en el caso de las enunciaciones con CP simple, las enunciaciones con PIC agregan un sentido suplementario que podría explicitarse mediante un 'si no surge ningún inconveniente' o 'si nada se interpone en el normal desarrollo de las cosas'. En otras palabras, las enunciaciones con PIC mantienen las AE y las AI de X pero matizadas por la propia incertidumbre de $\mathrm{L}$ frente al devenir de los acontecimientos futuros. De este modo, entonces, si la representación del decir evocado en el MD sobre el que encadena la enunciación con PIC es la de un decir que se presenta como confiable, la reserva se relaciona con la posición subjetiva de incertidumbre manifiesta en la enunciación de L. Como se observa en (5a), (26a) y (27a), esa posición de incertidumbre puede hacerse explícita mediante la inserción de la condicional sin que ello altere la lectura del PIC.

5. a.- ¿Qué sabes de Juan?

- Llegaba el martes, si no surge ningún inconveniente.

26. a.-¿Qué tal sigue Ana?

- Mejor, me parece. No la vi, porque cuando llegué, dormía. Pero había comido algo y tenía menos fiebre. Esta noche, la veía, si todo sigue igual, el médico de nuevo.

27. a.- Esta noche, si nada se interpone, le daban el alta.

Muy distinto es el caso de los enunciados con CP, como (33). Dado que la reserva en ellos no se relaciona con una incertidumbre de L sobre lo que puede suceder en el futuro, la inserción de la condicional "si todo sale bien" modifica la interpretación del condicional: tal como se constata en (34), ya no se trata del condicional que responde a un MD citativo, sino del uso de dicho tiempo como condicional hipotético. 
33. Mañana le darían el alta.

34. Mañana, si todo sale bien, le darían el alta.

En suma, por la presencia de PdV evidenciales originados en los PIC, la relación dialógica entre el posicionamiento subjetivo que emerge en (5), (26) y (27) y la causa evidencial citativa que desencadena en cada caso la enunciación puede glosarse como sigue:

[como creo $(\lambda)$ que $X$ (eso que me dijo $A$ ) es así, pero sé $(\lambda)$ que el futuro es impredecible], el posicionamiento subjetivo (L) es de reproducción confiada, pero prudente

Permítaseme aquí una última precisión respecto del PIC. Si, en gran parte de sus empleos, el PIC alude a acontecimientos futuros, debe subrayarse que también puede ocurrir en contextos interrogativos en los que no indica posterioridad. Es lo que sucede, por ejemplo, en (35) y (36)

35. Perdón, ¿cómo te llamabas?

36. ¿Cuándo teníamos que volver a verlo?

Al igual que en los ejemplos antes analizados, los PIC 'llamabas' y 'teníamos' vehiculizan $\mathrm{PdV}$ evidenciales citativos $\mathrm{y}$, en este sentido, el $\mathrm{MD}$ al que responde la enunciación en cada caso también se relaciona con un discurso de alguien específico (en (35) y en (36), el del interlocutor) que $\lambda$, la representación discursiva del locutor en tanto ser del mundo, cree o supone verdadero. Sin embargo, a diferencia de (5), (26) y (27), la cautela que se manifiesta en (35) y (36) no se vincula con la propia incertidumbre de $\mathrm{L}$ respecto de lo que puede suceder en el futuro. Antes bien, tal como lo muestra el posicionamiento subjetivo de pedido cortés de rememoración que se expresa en la enunciación, la atenuación se relaciona con el acto mismo del pedido ante el reconocimiento de que $\mathrm{X}$ fue dicho y de que, a pesar de ello, $\mathrm{L}$ no lo recuerda. En este sentido, el MD y el posicionamiento subjetivo con el que la enunciación con PIC responde en estos casos pueden esquematizarse como sigue:

[Me dijiste X SE no recuerdo $(\lambda) \mathrm{X}$ ]

POR LO TANTO

Enunciación de pedido cortés de rememoración de $X$ de $L$

De este modo, entonces, si la representación del decir evocado en el MD sobre el que encadena el PIC es la de un decir que se presenta como confiable (sus AE y sus AI quedan mantenidas), la enunciación prudente y cautelosa debe relacionarse con la reiteración de un pedido acerca de una información que L reconoce haber olvidado:

[como a pesar de que dijiste $\mathrm{X}$, no recuerdo $(\lambda) \mathrm{X}$ ], el posicionamiento subjetivo (L) es de pedido cortés de rememoración de $X$. 


\section{CONCLUSIONES}

En los estudios sobre evidencialidad citativa, se afirma que la fuente de la información que el hablante comunica en su enunciado procede de una cita de un discurso ajeno. Y ya sea que se trate de $2^{\mathrm{a}}$ o de $3^{\mathrm{a}}$ mano, la fuente siempre es vista del mismo modo (i.e., como una cita) y su presencia siempre implica la reserva o precaución epistemológica del hablante frente a lo que dice.

Por mi parte, en este trabajo, he buscado explicar las importantes diferencias de sentido que se manifiestan en las enunciaciones con PdV evidenciales citativos. Para ello, y en el marco de la perspectiva no referencialista de la significación y no unicista ni intencionalista del sujeto que propone del EDAP, he propuesto un análisis de los PdV vehiculizados por los usos citativos del futuro (morfológico y perifrástico), del condicional (periodístico y científico) y del imperfecto.

He intentado mostrar así que, en todos los casos, esos PdV exigen recuperar MD citativos que se muestran como la causa de la enunciación en la que esos PdV se expresan. Constituidos por encadenamientos argumentativos en los que una determinada representación discursiva de un decir evocado queda articulada en PLT o en SE con aserciones de $\lambda$ respecto de ese decir y distintos en cada caso, esos MD explican el posicionamiento subjetivo que queda plasmado en la enunciación. Pero hay más: en términos argumentativos, según se trate del FM, del FP, del CP, del CC o del PIC, ese posicionamiento se explica por el mantenimiento, el rechazo, la simple reproducción, etc. de las distintas AI y AE evocadas por la X del MD al que la enunciación responde dialógicamente.

FM:

[Dicen/dijeron/se dice X PLT admito $(\lambda)$ que X es posible] POR LO TANTO

Enunciación concesiva (se conserva la AI pero no las AE de X) FP:

[Dicen/dijeron/se dice X SE no estoy de acuerdo $(\lambda) \operatorname{con} \mathrm{X}]$

POR LO TANTO

Enunciación refutativa (se rechazan las AE y AI de X) CP:

[Se dice X SE no pude $(\lambda)$ corroborar X]

\section{POR LO TANTO}

Enunciación de reproducción precavida y resguardada (se conservan las AE pero no la AI de X)

CC:

[A dijo X PLT todos (incluido $\lambda$ ) en el campo disciplinario sabemos que $\mathrm{X}$ ha sido dicho por $\mathrm{A}]$

POR LO TANTO 
Enunciación de reproducción distanciada (se reproducen la AI y las AE de X sin asertarlas como propias)

PIC:

[A me dijo X PLT creo $(\lambda)$ que X es así]

\section{POR LO TANTO}

Enunciación de reproducción confiada, pero prudente (se conservan la AI y las AE de $\mathrm{X}$ vistas a la luz de la incertidumbre sobre el devenir)

\section{[Me dijiste X SE no recuerdo $(\lambda) \mathrm{X}$ ]}

\section{POR LO TANTO}

Enunciación confiada de pedido cortés de rememoración (se conservan la AI y las $\mathrm{AE}$ de $\mathrm{X}$ aun cuando no se las recuerde)

Finalmente, el análisis aquí propuesto también ha permitido dar cuenta de las diferentes imágenes del decir evocado en el MD. En efecto, según se trate de enunciaciones concesivas (en el caso del FM), refutativas (en el del FP), precavidas y resguardadas (en el del CP), distanciadas (en el del CC) o confiadas (en el de PIC), esas respuestas dialógicas harán ver los decires evocados en el MD como plausibles o aceptables pero solo en parte acertados; como inadmisibles o errados; como no verificados o no confirmados; como un decir calificado o como un decir confiable, respectivamente.

FM:

FP:

[Decir plausible, pero solo en parte acertado y justificado] Enunciación concesiva $P$ :

[Decir inadmisible/infundado/errado] Enunciación refutativa

CP:

\section{$\checkmark D$}

[Decir no confirmado que aún no puede darse por cierto] Enunciación de reproducción precavida y resguardada

CC: PIC:

[Decir calificado] $\nearrow^{\text {Enunciación de reproducción distanciada por reconocimiento enunciativo }}$

[Decir confiable] Enunciación de reproducción confiada, pero prudente/Enunciación confiada $\checkmark$ de pedido cortés de rememoración

En suma, al enfocar el análisis del significado evidencial en el modo en que quedan representadas argumentativamente las causas evidenciales que desencadenan la enunciación -y no en las fuentes de información del sujeto hablante-, el estudio ha podido dar cuenta de la especificidad semántica del empleo citativo de los distintos tiempos verbales aquí considerados y de cómo cada uno de ellos contribuye a la construcción del sentido del discurso. 


\section{REFERENCIAS BIBLIOGRÁFICAS}

Aikhenvald, A. (2004). Evidentiality. Oxford: Oxford University Press

Bajtín, M. (198). Discourse in the novel. En M. Holquist (Ed.), The Dialogical Imagination (pp. 259-422). Austin: University of Texas Press.

Bajtín, M. (1982). Estética de la creación verbal. México: Siglo XXI.

Beke, R. (2005). El metadiscurso interpersonal en artículos de investigación. Revista Signos. Estudios de Lingüistica, 38(57), 7-18

Bermúdez, F. (2004). La categoría evidencial del castellano: Metonimia y elevación de sujeto. Boletin de Lingüistica, 22, 3-31.

Bermúdez, F. (2005a). Evidencialidad. La codificación lingüistica del punto de vista. Tesis doctoral, Universidad de Estocolmo, Estocolmo, Suecia.

Bermúdez, F. (2005b). Los tiempos verbales como marcadores evidenciales: El caso del pretérito perfecto compuesto. Estudios Filológicos, 40, 165-188.

Bermúdez, F. (2016). Rumores y otros malos hábitos. El condicional evidencial en español. Cuadernos de Lingüistica de El Colegio de México, 3(2), 35-69.

Böhm, V. \& Hennemann, A. (2014). The evidential use of the Spanish imperfect and the conditional in journalistic contexts. Studia Neophilologica, 86, 1-18.

Carel, M. \& Ducrot, O. (2005). La semántica argumentativa: Una introducción a la teoría de los bloques semánticos. Buenos Aires: Colihue.

Cartagena, N. (1999). Los tiempos compuestos. En I. Bosque \& V. Demonte (Eds.), Gramática descriptiva de la lengua española (pp. 2936-2975). Madrid: Espasa.

Cornillie, B. (2007). Evidentiality and epistemic Modality in Spanish (semi-) auxiliaries. A cognitive-functional approach. Berlín: Mouton de Gruyter.

Cornillie, B. \& Gras Manzano, P. (2015). On the interactional dimension of evidentials. The case of the Spanish discourse markers. Discourse Studies, 17(2), 141-161.

Chafe, W. (1986). Evidentiality in English conversation and academic Writing. En W. Chafe \& J. Nichols (Eds.), Evidentiality. The Linguistic Coding of Epistemology (pp. 261-272). Norwood: Alex Publishing.

De Haan, F. (1999). Evidentiality and epistemic modality: Setting boundaries. Soutbwest Journal of Linguistics, 18, 83-101.

Dendale, P. \& Tasmowski, L. (2001). Introduction: Evidentiality and related notions, Journal of Pragmatics, 33, 339-348 
Ducrot, O. (1984). Le dire et le dit. París: Minuit.

Ducrot, O. (2001). Quelques raisons de distinguer locuteurs et énonciateurs. Polyphonie-linguistique et littéraire III, 19-41.

Ducrot, O. (2004). Sentido y argumentación. En E. Arnoux \& M. M. García Negroni (Eds.), Homenaje a Oswald Ducrot (pp. 359-370). Buenos Aires: Eudeba.

Escandell Vidal, M. V. (2010). Futuro y evidencialidad. Anuario de Lingüística Hispánica, 26, 9-34.

Ferrari, L. (2004). Modalidad epistémica y grados de certeza en los artículos de investigación [en la revista Medicina]. Discurso, Teoría y Análisis, 26, 41-60.

Ferrari, L. (2009). Modalidad epistémica y evidencialidad en las conclusiones de artículos de investigación. Debate terminológico, 06, 1-23.

García Negroni, M. M. (2016). Polifonía, evidencialidad citativa y tiempos verbales. Acerca de los usos citativos del futuro morfológico y del futuro perifrástico. En R. González Ruiz, D. Izquierdo Alegría \& Ó. Loureda Lamas (Eds.). La evidencialidad en español: Teoría y descripción (pp. 279-302). Gradun. Universidad de Navarra / Universität Heidelberg. Editorial Vervuert/Iberoamericana.

García Negroni, M. M. (2018a). Argumentación y puntos de vista evidenciales: Acerca del condicional citativo en el discurso periodístico y en el discurso científico. Boletin de Lingüistica, XXX(49-50), 86-109.

García Negroni, M. M. (2018b). Argumentación y puntos de vista evidenciales citativos: Acerca de la negación metadiscursiva en el discurso político. Oralia, $21(2), 223-242$.

García Negroni, M. M. (2019). El enfoque dialógico de la argumentación y la polifonía, puntos de vista evidenciales y puntos de vista alusivos. Rilce. Revista de Filología Hispánica, 35(2), 521-549.

García Negroni, M. M. \& Hall, B. (2020). Procesos de subjetivación y lenguaje inclusivo. Literatura y Lingüística, 42, 275-301.

García Negroni, M. M. \& Libenson, M. (2019). A propósito de las causas dialógicas de la enunciación. El caso de las enunciaciones mirativas con el marcador Mirá. Ponencia presentada en el 6th International Conference Discourse Markers in Romance Languages: Crosslinguistic approaches in Romance and beyond. Universidad de Bérgamo, Bérgamo, Italia. 
García Negroni, M. M. \& Libenson, M. (2020a). “'Al final tenías plata! Acerca de las causas mirativo-evidenciales de la enunciación. En R. Maldonado \& J. De la Mora (Eds.), Evidencialidad. Determinaciones léxicas y construccionales (pp. 243-264). Ciudad de México: Universidad Nacional Autónoma de México y Universidad Autónoma de Querétaro.

García Negroni, M. M. \& Libenson, M. (2020b). Aportes del Enfoque dialógico de la argumentación y de la polifonía al estudio del significado evidencial: ¿Y (tono circunflejo)...X? y ¿Así que X? en contraste. En A. Messias Nogueira, C. Fuentes Rodríguez \& M. Martí (Coords.), Aportaciones desde el español y el portugués a los marcadores del discurso. Treinta años después de Martín Zorraquino y Portolés (pp. 77-97). Sevilla: Editorial de la Universidad de Sevilla.

García Negroni, M. M. \& Libenson, M. (2020c). La evidencialidad desde el Enfoque dialógico de la argumentación y de la polifonía. Un estudio contrastivo de los empleos inferencial y citativo del marcador evidencial asi que. En Ó. Loureda \& M. Rudka (Eds.), Marcadores del discurso y lingüistica contrastiva en las lenguas románicas (pp. 41-62). Madrid/Frankfurt: Iberoamericana/Vervuert.

Gennari, S. (2002). Spanish past and future tenses: Less (semantics) is more. En J. Gutiérrez-Rexach (Ed.), From words to discourse: Trends in Spanish semantics and pragmatics (pp. 21-36). Ámsterdam: Elsevier [en línea]. Disponible en: http://eventcognition.org/silvia gennari/resources/Spanish tenses.pdf)

Gómez Torrego, L. (1999). Los verbos auxiliares. Las perífrasis verbales de infinitivo. En I. Bosque \& V. Demonte (Eds.), Gramática descriptiva de la lengua española (pp. 3323-3389). Madrid: Espasa.

González Ruiz, R., Izquierdo Alegría, D. \& Loureda, Ó. (Eds.) (2016). La evidencialidad en español: Teoría y descripción. Madrid: Iberoamericana/Frankfurt am Main: Vervuert.

González Vázquez, M. (2016). La naturaleza y función de la evidencialidad en español. En R. González Ruiz, D. Izquierdo Alegría \& Ó. Loureda Lamas (Eds.), La evidencialidad en español: Teoría y descripción (pp. 49-74). Madrid: Iberoamericana/Frankfurt am Main: Vervuert.

González Vergara, C. (2011). Estrategias gramaticales de expresión de la evidencialidad en el español de Chile. Alpha, 32, 149-165.

Hassler, G. (2017). Intersección entre la evidencialidad y la atenuación: El pretérito imperfecto evidencial y el futuro narrativo. Normas, 7(2), 19-33.

Hyland, K. (2000). Disciplinary discourses: Social interactions in academic writing. Harlow: Longman. 
Kornfeld, L. (2014). Lecturas alternativas del futuro usos y significados de la perífrasis ir a + infinitivo. Translaciones, 1(1), 8-29.

Kronning, H. (2012). Le conditionnel épistémique: Propriétés et fonctions discursives. Langue française, 173, 83-97.

Kronning, H. (2015). El condicional epistémico ‘de atribución' en francés, italiano y español: Aspectos diafásicos, diatópicos y diacrónicos. En J. Kragh \& J. Lindschouw (Eds.), Les variations diasystématiques et leurs interdépendances dans les langues romanes (pp. 507-518). Estrasburgo: Éditions de linguistique et de philologie.

Leonetti, M. \& Escandell Vidal, M.V. (2003). On the quotative readings of Spanish Imperfecto. Cuadernos de Lingüistica, 10, 135-154.

Maldonado, R. \& De la Mora, J. (Eds.) (2020). Evidencialidad. Determinaciones léxicas y construccionales. México: Universidad Nacional Autónoma de México y Universidad Autónoma de Querétaro.

RAE y AALE (2009). Nueva gramática de la lengua española. Madrid: Espasa.

Reyes, G. (1990). Valores estilísticos del imperfecto. Revista de Filología Española, LXX(1/2), 45-70.

Reyes, G. (1994). Los procedimientos de cita: Citas encubiertas y ecos. Madrid: Arco Libros

Rodríguez Ramalle, M. T. (2014). Sobre marcadores y su relación con la modalidad evidencial. En M. M. García Negroni (Ed.), Marcadores del discurso: Perspectivas y contrastes (pp. 233-250). Buenos Aires: Santiago Arcos.

Rodríguez Ramalle, M. T. (2017). Partículas evidenciales en el desarrollo del discurso reformulativo. En R. González Ruiz, D. Izquierdo Alegría \& Ó. Loureda (Eds.), La evidencialidad en español: Teoría y descripción (pp. 179-199). Madrid: Iberoamericana/Frankfurt am Main: Vervuert.

Rodríguez Rosique, S. (2019). El futuro en español. Tiempo, conocimiento, interacción. Berlín: Peter Lang.

Rojo, G. (1974). La temporalidad verbal en español. Verba I, 68-149.

Rojo, G. \& Veiga, A. (1999). El tiempo verbal. Los tiempos simples. En I. Bosque \& V. Demonte (Eds.), Gramática descriptiva de la lengua española (pp. 2867-2934). Madrid: Espasa Calpe.

Soto, G. (2008). Sobre el llamado futuro de probabilidad. Algunas condiciones del valor modal de -ré. Boletin de Filología, XLIII, 193-206. 
Van der Auwera, J. \& Plungian, V. (1998). Modality's semantic map. Linguistic Typology, 2(1), 79-124.

Vatrican, A. (2014). Usos y valores modales del condicional en español. Archivum, 64, 239-274.

Willett, Th. (1988). A cross-linguistic survey of the grammaticalization of evidentiality. Studies in Language, 2, 51-97.

\section{NOTAS}

${ }^{1}$ El presente trabajo se inscribe en el proyecto de investigación PICT 2943/17 "El enfoque dialógico de la argumentación y de la polifonía. Un modelo semántico-pragmático para el análisis de la subjetividad y de la alteridad en distintos géneros discursivos", subvencionado por la Agencia Nacional de Promoción Científica y Tecnológica, Argentina.

${ }^{2}$ La taxonomía de Willett (1988) no es por supuesto la única que se ha propuesto. Así, por ejemplo, desde una perspectiva tipológica, Aikhenvald (2004) clasifica los sistemas evidenciales según especifiquen o no la fuente de información para luego clasificar aquellos que sí la especifican según la cantidad de distinciones que realicen (dos, tres, cuatro o cinco). Para ello, toma en consideración 6 parámetros semánticos recurrentes en las lenguas con evidencialidad gramatical: a) visual (para la información adquirida a través de la vista); b) sensorial no visual (para aquella adquirida a través de los otros sentidos); c) inferencia (basada en evidencia visible o tangible, o resultado); d) supuesta (basada en evidencias que no son resultados visibles, por ej., razonamiento lógico o conocimientos generales); e) transmitida (para la información citada pero sin referencia al origen de la voz citada); f) citativa (para la información transmitida con clara referencia a la fuente de la cita). Para otras clasificaciones del dominio evidencial, podrá consultarse, por ejemplo, Bermúdez (2005a), quien desde una óptica cognitivista, propone una caracterización de la evidencialidad articulada en torno a tres parámetros concebidos como continuos: modo de acceso a la información (sensorial/cognitivo), fuente de información (personal/ajena) y acceso a la información (privativo/universal).

3 Al respecto, entre muchos otros, podrán consultarse los trabajos de Reyes, 1990, 1994; Leonetti y Escandell Vidal, 2003; Bermúdez, 2004, 2005a, 2005b, 2016; Cornillie, 2007; Escandell Vidal, 2010; Rodríguez Ramalle, 2014, 2016; Böhm y Hennemann, 2014; Cornillie y Gras Manzano, 2015; González Ruiz, Izquierdo Alegría y Loureda, 2016; Hassler, 2017; Maldonado y De la Mora, 2020.

${ }^{4}$ Si bien en algunos trabajos sobre evidencialidad (por ej., Aikhenvald, 2004; González Vergara, 2011), se distingue entre evidencialidad indirecta transmitida o reportativa (para la información citada pero sin referencia al origen de la voz citada) y evidencialidad indirecta citativa (para la información transmitida con clara referencia a la fuente de la cita), en este trabajo, no se hará foco en esa distinción.

${ }^{5}$ Como se recordará, según Ducrot (1984), las instrucciones causales (i.e., las referidas a la cualificación del habla por su causa) permiten, junto con las polifónicas, ilocucionarias y 
argumentativas, dar cuenta del sentido del enunciado, es decir de la representación que el enunciado brinda de su propia enunciación. El EDAP incorpora a estas instrucciones, las dialógico-causales, que refieren a la identificación del marco de discurso al que la enunciación responde con un cierto posicionamiento subjetivo.

${ }^{6} \mathrm{Al}$ igual que Rojo (1974), Rojo y Veiga (1999) y Gennari (2002), Bermúdez (2005a) no toma en consideración el caso del FP.

${ }^{7}$ Aunque enmarcado en una tradición diferente, la Gramática Funcional de Dik, Soto (2008: 199) propone la noción de eco para dar cuenta de enunciados semejantes a los aquí analizados. Así, en 'La fruta caerá del árbol, como tú dices, pero para mí que todavía está verde', "la construcción hace eco de una proposición que se admite y que va en el satélite de una relación retórica de concesión en que el núcleo lo constituye la cláusula que sigue a pero". Según el autor, en estos casos, el contexto permite inferir una aspectualidad cuantificatoria iterativa y una aspectualidad de fase continuativa lo que determina una predicación estativa derivada que bloquea la lectura de futuro y hace surgir la de modalidad.

${ }^{8}$ Para Rodríguez Rosique (2019), este empleo concesivo del futuro genera un efecto atenuador o desrealizante. Según la autora, al utilizar el futuro, "el hablante no se limita a aceptar (...) la propuesta del interlocutor -como lo haría el presente-, sino que la acepta a regañadientes o de mala gana".

${ }^{9}$ Cf. Ma qué va a estar viendo a los jugadores; Minga que va a estar viendo a los jugadores; $V$ a a estar viendo a los jugadores y todo; Mirá si va a estar viendo a los jugadores. En relación con mirá si FP, debe señalarse que, además del valor refutativo, la estructura presenta un valor mirativo de contraexpectativa (al respecto, podrá consultarse García Negroni \& Libenson, 2019).

${ }^{10}$ En este sentido, se trata, en términos de Reyes (1994), de casos de discursos indirectos encubiertos, lo que permite diferenciarlos de aquellos casos en los que el CP vehiculiza un PdV evidencial inferencial. Compárese al respecto los CP de (3) y (9), que vehiculizan PdV citativos, con, por ejemplo, el siguiente fragmento (título y comienzo de la nota) extraído de Pulso, México, 17/5/2013: "Mujer que se suicidó en el Metro lo habría pensado 2 horas [título]. La mujer que se lanzó la tarde del miércoles a las vías del Metro en la estación Puebla, deambuló dos horas por el andén. Las cámaras de seguridad del Sistema de Transporte Colectivo (STC) la captaron cuando arribó a los pasillos. Eran alrededor de las 17:00 horas cuando se le observa en la estación hacia Tacubaya, con su hija de unos seis meses en brazos. (...) Durante esas dos horas, de las 17:00 a las 19:00, las de mayor afluencia de pasajeros, la mujer vio pasar unos 50 trenes. (...) Se colocó al inicio del andén, por donde ingresa el tren. En al menos dos ocasiones se acercó a la orilla segundos antes de que llegara el convoy. El camino que la mujer siguió antes de caer a las vías caracteriza a las personas que deciden suicidarse".Tal como puede verificarse, las instrucciones semánticas asociadas al condicional habría pensado, en el titular de la noticia, llevan a comprender la enunciación no como plenamente asumida por el locutor. Y ello es porque, plasmado por el condicional, el PdV evidencial inferencial exige buscar el fundamento o la razón de esa enunciación conjetural que lo contiene en un $M D$ relativo a ciertos indicios perceptuales o discursivos (i.e., Veo/Dicen Y por lo tanto infiero X) a partir del cual ella queda justificada. El enunciado no presenta así un locutor que declara que la mujer pensó en suicidarse, sino que muestra un sujeto que, basado en ciertas pruebas o indicios a los que se alude, luego, en el cuerpo de la nota (i.e., las cámaras de seguridad del STC registraron la actitud de la 
mujer durante los 120 minutos que precedieron a la caída mortal, por lo tanto infiero que dudó mucho), afirma con precaución epistemológica su conclusión: la mujer habria pensado durante 2 horas si suicidarse o no.

${ }^{11}$ En todos los casos aquí ejemplificados, el CP es el compuesto y, en tanto tal, corresponde a acontecimientos pasados, pero el mismo tipo de enunciación precavida y resguardada de L también aparecería si el CP fuera el simple y aludiera entonces a un hecho presente o futuro (cfr. por ej., Colombia estaría negociando vacunas de los laboratorios chinos Sinovac y Sinopharm; La semana próxima, Diputados trataria el proyecto de reforma del impuesto a las ganancias). En este caso, la argumentación evocada por la $\mathrm{X}$ incluida en el MD al que respondería la enunciación con $\mathrm{CP}$ aludiría a un evento presente o futuro.

12 Como observa Kronning (2012: 87), "el CE [condicional epistémico] [...] tiene una orientación modal invariablemente positiva".

13 En este sentido, el CC puede verse como uno de los recursos de 'mitigación' o hedges (Hyland, 2000), característicos del discurso científico-académico. Para un estudio de las estructuras condicionales y de los verbos en condicional como hedges que permiten modalizar epistémicamente las proposiciones, podrá consultarse, por ejemplo, Beke (2005); Ferrari (2004, 2009).

${ }^{14}$ Agradezco a uno de los evaluadores anónimos el haberme hecho notar que la perífrasis ir a + infinitivo en imperfecto ofrece una paráfrasis posible para estos enunciados (cf. Esta noche la iba a ver el médico de nuevo; Esta noche le iban a dar el alta). En este tipo de empleos en que el evento denotado es futuro y la perífrasis está en imperfecto, el posicionamiento subjetivo es, en efecto, de reproducción confiada pero prudente. Ha de verse, sin embargo, que si la misma perífrasis en imperfecto referida a un evento futuro apareciera acompañada de un marcador refutativo del tipo de qué, ma qué, minga que, mirá si, ella adquiriría el mismo valor refutativo analizado en 2.1. (cf. mirá si esta noche la iba a ver el médico de nuevo; minga que la iba a ver de nuevo; ma qué la iba a ver de nuevo; la iba a ver de nuevo y todo). 